\title{
Adenovirus-mediated RAR- $\beta$ over-expression enhances ATRA-induced neuronal differentiation of rat mesenchymal stem cells
}

\author{
Yang Bi, Min Gong, Yun He, Xiaoping Wei, Jie Chen, Tingyu Li
}

Nutritional Research Center and Key Laboratory of Developmental Diseases in Childhood, Ministry of Education, Children's Hospital, Chongqing Medical University, Chongqing, China

Submitted: 30 November 2011

Accepted: 22 February 2012

Arch Med Sci 2013; 9, 2: 314-322

DOI: $10.5114 /$ aoms.2012.31410

Copyright @ 2013 Termedia \& Banach

\section{Abstract}

Introduction: The retinoic acid (RA) signaling pathway plays important roles in neural development. All-trans retinoic acid (ATRA) activates the RA signal by regulating RAR- $\beta$ in mesenchymal stem cell (MSC)-derived neuron cells. Here, we try to investigate whether RAR- $\beta$ over-expression can affect neuronal differentiation of MSCs.

Material and methods: The RAR- $\beta$ gene was constructed into adenovirus Ad-RAR- $\beta$ by using the AdEasy system. The MSCs were infected with Ad-RAR- $\beta$. Real timepolymerase chain reaction (RT-PCR), Western blot and immunofluorescence were performed to detect the expression and localization of RAR- $\beta$. The MSCs were treated with $1 \mu \mathrm{mol} / /$ ATRA and modified neuronal induction medium (MNM). Soma size and axon length of induced neurons were measured. Neural specific markers were detected by RT-PCR, western blot and immunofluorescence to evaluate neuronal differentiation.

Results: The 1300 bp fragment of RAR- $\beta$ gene was confirmed to be correctly cloned in the adenovirus vector. Cloudiness amplification of Ad-RAR- $\beta$ was observed in HEK293 cells during package. After $48 \mathrm{~h}$ of Ad-RAR- $\beta$ infection, about $70 \%$ of MSCs were RFP-positive. RAR- $\beta$ expression was increased by about 1988 -fold and located in the nucleus. RAR- $\beta$ over-expression did not affect neuronal differentiation efficiency; however, soma size of induced neuron cells enlarged from $716.25 \pm 95.96 \mu \mathrm{m}^{2}$ to $1160.12 \pm 352.65 \mu \mathrm{m}^{2}$ and axon length from $64.17 \pm 11.88 \mu \mathrm{m}$ to $83.98 \pm 13.69 \mu \mathrm{m}$. Neural markers other than nestin $-\mathrm{NSE}$, MAP-2, Tau, and Tuj 1 - were increased by 4 - to 11-fold in RAR- $\beta$ over-expressed neuron cells with ATRA/MNM induction compared with the Ad-null control group. Conclusions: Our results have demonstrated that adenovirus-mediated RAR- $\beta$ over-expression could facilitate neuron cell types of MSCs in vitro, indicating that the RAR- $\beta$-activated RA signal might be a vital factor in neuronal differentiation.

Key words: mesenchymal stem cells, all-trans retinoic acid, retinoic acid receptor $\beta$, neuronal differentiation.

\section{Introduction}

Perinatal hypoxic-ischemic encephalopathy (HIE) is an important disease of brain injury without a good treatment [1]. Neural stem cell transplantation in a brain damage animal model has shown its potential therapeutic applications in neuronal disease [2, 3]. Mesenchymal stem cells (MSCs)

\author{
Corresponding author: \\ Tingyu Li \\ Jie Chen \\ Nutritional Research Center \\ Children's Hospital \\ Chongqing Medical University \\ Chongqing 400014, China \\ Phone: +86 2363630913 \\ Fax: +862363626904 \\ E-mail: tyli@vip.sina.com \\ E-mail: jchen010@gmail.com
}


are adult stem cells with characteristics of easy isolation, self-renewal, multi-potential and low immunogenicity, which have been widely used in tissue engineering to regenerate different cells/tissues and repair damaged tissues $[4,5]$. Many reports have indicated that MSCs can differentiate into neuron cells under appropriate cellular conditions in vitro and recover learning ability and spatial memory after being transplanted into hypoxic-ischemic brain damage (HIBD) rats $[6,7]$. However, compared to the high differentiation efficacy of neuron cells derived from MSCs in vitro, differentiation efficacy of MSCs in vivo and its role of functional replacement were relatively lower $[6,8]$. Therefore, it is definitely required to explore a more reliable method to induce specific neuron cell types.

The retinoic acid signaling pathway can regulate gene expression and modulate a wide variety of biological processes including cell proliferation, differentiation, apoptosis and immuno-regulation [9]. We have reported that vitamin A level in vivo may affect the differentiation into mature and functional neuron cells from MSCs [7]. All-trans retinoic acid (ATRA), an active form of vitamin A, broadly participates in embryonic nervous system development and nerve cell differentiation [10]. In our previous study, ATRA treatment activated the RA signaling pathway by up-regulating retinoic acid receptor $\beta$ (RAR- $\beta$ ) expression and subsequently promoted neuronal differentiation of MSCS [11]. Thus, we hypothesize that over-expression of RAR- $\beta$ might activate RA signaling and further improve ATRA-induced neuronal differentiation of MSCs. Here, we induced RAR- $\beta$ over-expression by using an adenovirus vector and investigated the effects of RAR- $\beta$ on neuronal differentiation of rat MSCS.

\section{Material and methods}

\section{Isolation of rat mesenchymal stem cells}

The animal study and all experiments were approved by the Ethical Committees of the Institute of Zoology and the Children's Hospital of Chongqing Medical University. Four-week old Sprague-Dawley rats were obtained from the Experimental Animal Centre of Chongqing Medical University. As in the previously reported method [12], rats were sacrificed by decapitation, then the tibias and femurs were isolated with clearance of connective and soft tissues. MSCs were harvested by flushing bone marrow and grown in Dulbecco's Modified Eagle Medium/Nutrient Mixture F12 (DMEM/F12, Hyclone, USA) supplemented with $10 \%$ fetal bovine serum (FBS, Hyclone, USA), 100 units $/ \mathrm{ml}$ penicillin, and $100 \mu \mathrm{g} / \mathrm{ml}$ streptomycin at $37^{\circ} \mathrm{C}$ in $5 \% \mathrm{CO}_{2}$. Cells were passaged at a confluency of $90 \%$. Three to 5 passages of MSCs were used for in vitro experiments.

\section{Construction of recombinant adenovirus vector containing rat RAR- $\beta$ gene}

Total RNA was isolated from PC12 cells and transcribed into CDNA. The coding region of rat RAR- $\beta$ was specifically amplified from the CDNA template of PC12 cells. The adenovirus was constructed using the AdEasy system [13]. Briefly, the PCR product was digested by two endonucleases BamH I and HinD III. The product was directional cloned into the pAdTraceTOX vector to construct the pAdTrace-RAR- $\beta$ plasmid. The correct recombinant pAdTrace-RAR- $\beta$ was linearized by Pme I, following co-transformation with the backbone vector pAdEasy-1 in Escherichia coli BJ5183 to obtain the recombinant adenovirus vector pAd-RAR- $\beta$. After being linearized by Pac I, the homologous recombinant pAd-RAR- $\beta$ was liposome (Lipofectamine $^{\text {TM }} 2000$, Invitrogen, USA) transfected into the HEK293 cell line to package the recombinant adenovirus vector containing the RAR- $\beta$ gene (Ad-RAR- $\beta$ ). High titer adenovirus was obtained by repeated infection in HEK293 cells.

\section{Adenovirus-mediated over-expression of RAR- $\beta$ in mesenchymal stem cells}

The MSCs were seeded in 6-well culture plates at a confluence of $50-60 \%$, and then adenovirus at multiplicity of infection (MOI) of 100 was added to the medium. After $48 \mathrm{~h}$ of infection, red fluorescent protein (RFP) was observed under a microscope (TE2000-S, Nikon, Japan). Cells $\left(1 \times 10^{6}\right)$ were collected and suspended in $1 \mathrm{ml}$ of $1 \%$ BSA PBS buffer. The ratio of RFP-positive to total cells was acquired by flow cytometry using a FACSCanto ${ }^{\mathrm{TM}}$ II system and Cell Quest Pro software (BD Biosciences). The RT-PCR, western blot and immunofluorescence were performed to detect the expression of RAR- $\beta$. An empty adenovirus (Ad-null) was used as an adenovirus control.

\section{ATRA-induced neuronal differentiation}

The MSCs were cultured in DMEM/F12 medium for $24 \mathrm{~h}$. Then DMEM/F12 medium containing $1 \mu \mathrm{mol} / \mathrm{l}$ ATRA (Sigma, USA, resolved in $100 \%$ ethanol at $10 \mathrm{mmol} / \mathrm{ml}$ storage concentration) was used to incubate with MSCs for $24 \mathrm{~h}$. Afterward, DMEM/F12 medium was removed, cells were washed with D-Hank's solution twice and induced with modified neuronal induction media (MNM) which was composed of DMEM/F12/100 units/ml penicillin, and $100 \mu \mathrm{g} / \mathrm{ml}$ streptomycin/1.6\% DMSO/160 $\mu \mathrm{mol} / \mathrm{l}$ $\mathrm{BHA} / 20 \mathrm{mmol} / \mathrm{l} \mathrm{KCl} / 1.6 \mathrm{mmol} / \mathrm{l}$ valproic acid/8 $\mu \mathrm{mol} / \mathrm{l}$ forskolin $/ 0.8 \mu \mathrm{mol} / \mathrm{l}$ hydrocortisone $/ 4 \mu \mathrm{g} / \mathrm{ml}$ insulin (all from Sigma, USA). Experimental MSCs were treated with ATRA/MNM induction, Ad-null infection and ATRA/MNM induction, Ad-RAR- $\beta$ infection and ATRA/MNM induction, respectively. In two adenovirus groups, MSCs were infected by adenovirus for $48 \mathrm{~h}$ before neuronal induction. The MSCs without any treatment were used as a negative control. 


\section{Quantitative analysis of neuronal differentiation}

Treated MSCs were stained for neuron related markers, nestin, neuron-specific enolase (NSE) and Tau. Images of ten non-overlapping fields of view were captured under a microscope (TE2000-S, Nikon, Japan). Positive stained cells with protruding soma, axons and dendrites were counted as induced neuron cells to calculate induction efficacy. The ImageJ program was used to measure the soma size and axon length. Three independent experiments were performed and two replicates were set in each experiment.

\section{RNA isolation and RT-PCR analysis}

As previously described [14], extraction of total RNA was carried out using an RNA extraction kit (Genemega Inc, USA) according to the manufacturer's instructions. Then, $10 \mu \mathrm{g}$ of total RNA was reverse transcribed into CDNA with random primer and Superscript II reverse transcriptase (TAKARA, Japan). The PCR templates were prepared with 5- to 10-fold dilution of the first strand CDNA products. The genes of interest were amplified with PCR primers (18-20 mers) which were designed using the Primer 3.0 program (Table I). The Bio-Rad protocol for realtime PCR amplification was performed as follows: $94^{\circ} \mathrm{C} \times 20^{\prime \prime}, 58^{\circ} \mathrm{C} \times 20^{\prime \prime}, 70^{\circ} \mathrm{C} \times 20^{\prime \prime}$ and reading plate for 40 cycles. Primary data of Ct value were taken to calculate fold change by normalizing each cDNA to GAPDH.

\section{Western blot analysis}

Western blot analysis and quantification were performed as previously described [14]. Briefly, treated MSCs from T25 culture flasks were collected and lysed with RAPI buffer containing PMSF. Approximately $20 \mu \mathrm{g}$ of total proteins per lane were loaded onto an $8-10 \%$ SDS/PAGE gel (Beyotime, China). Electrophoretic separation was performed at an applied voltage of $120 \mathrm{~V}$ for $1.5-4 \mathrm{~h}$ in SDS running buffer. Then, proteins were transferred to an Immobilon-P membrane (Millipore, Billerica, USA). After blocking with $5 \%$ fat-free skimmed milk in Trisbuffered saline buffer containing 0.05\% Tween-20 at room temperature for $1 \mathrm{~h}$, the membrane was incu- bated with anti-NSE (Abcam, USA), anti-neuronspecific class III $\beta$-tubulin (Tuj1) (Abcam, USA) or anti- $\beta$-actin (Santa Cruz Biotechnology, USA) primary antibody at $4^{\circ} \mathrm{C}$ overnight respectively, followed by incubation with an appropriate secondary antibody conjugated with horseradish peroxidase (Santa Cruz Biotechnology, USA) at room temperature for $1 \mathrm{~h}$. The presence of the proteins was detected and quantified by using Luminata Crescendo Western HRP Substrate (Millipore, Billerica, USA) with the Syngene GBox Image Station.

\section{Immunofluorescence staining}

Immunofluorescence staining was carried out using previous methods [14]. First, treated MSCs were fixed with methanol at $-20^{\circ} \mathrm{C}$ for $15 \mathrm{~min}$ and blocked with $5 \%$ bovine serum albumin at room temperature for $1 \mathrm{~h}$, followed by incubation with NSE, nestin or Tau primary antibody (all from Abcam, USA) at $4^{\circ} \mathrm{C}$ overnight. After washing twice, DyLight 488 conjugated secondary antibody (Jackson ImmunoResearch Laboratories, Inc, USA) was added to incubate cells at room temperature for $30 \mathrm{~min}$. DAPI (Sigma, USA) was used to stain nuclei. The presence of the proteins was examined under a reverse fluorescence microscope (TE2000-S, Nikon, Japan). Untreated MSCs stained by non-specific IgG were used as negative controls.

\section{Statistical analysis}

All data were analyzed using the SPSS 15.0 software package and presented as mean \pm standard deviation (SD). A two-tailed Student's $t$-test assuming equal variances was performed to measure significant differences between two samples. A $p<0.05$ was considered statistically significant.

\section{Results}

\section{Construction of recombinant adenovirus vector containing rat RAR- $\beta$ gene}

An approximately $1300 \mathrm{bp}$ fragment of the fulllength RAR- $\beta$ gene was PCR amplified from the recombinant adenoviral plasmid pAd-RAR- $\beta$, and a specific 4500 bp fragment was digested by Pac I

Table I. RT-PCR Primers (5'-3')

\begin{tabular}{|lll|}
\hline Variable & Forward & Reverse \\
\hline $\begin{array}{l}\text { RAR- } \beta \\
\text { full length }\end{array}$ & $\begin{array}{l}\text { GACGGATCCACCACCATGGGCATG } \\
\text { TTTGACTGTATGGATGTTC }\end{array}$ & $\begin{array}{l}\text { CACAAGCTTTCACTGCAGCAGC } \\
\text { GGGGACTGGCTCAC }\end{array}$ \\
\hline RAR- $\beta$ & AAAGCCCACCAGGAAACC & CTTGGCGAACTCCACGAT \\
\hline GAPDH & TGGATGGTCCCTCTGGAA & GTGAGCTTCCCGTTCAGC \\
\hline nestin & GGGCAAGTGGAACGTAGA & TCCCACCGCTGTTGATTT \\
\hline NSE & CTGTTTGCTGCTCAAGGTC & TCCCACTACGAGGTCTGC \\
\hline MAP-2 & GTATCAGGAGACAGGGAGGAG & GGGGTAGTAGGTGTTGAGGTG \\
\hline Tau & AAAGGTGGCAGTGGTTCG & GGCTGGTGCTTCAGGTTC \\
\hline
\end{tabular}



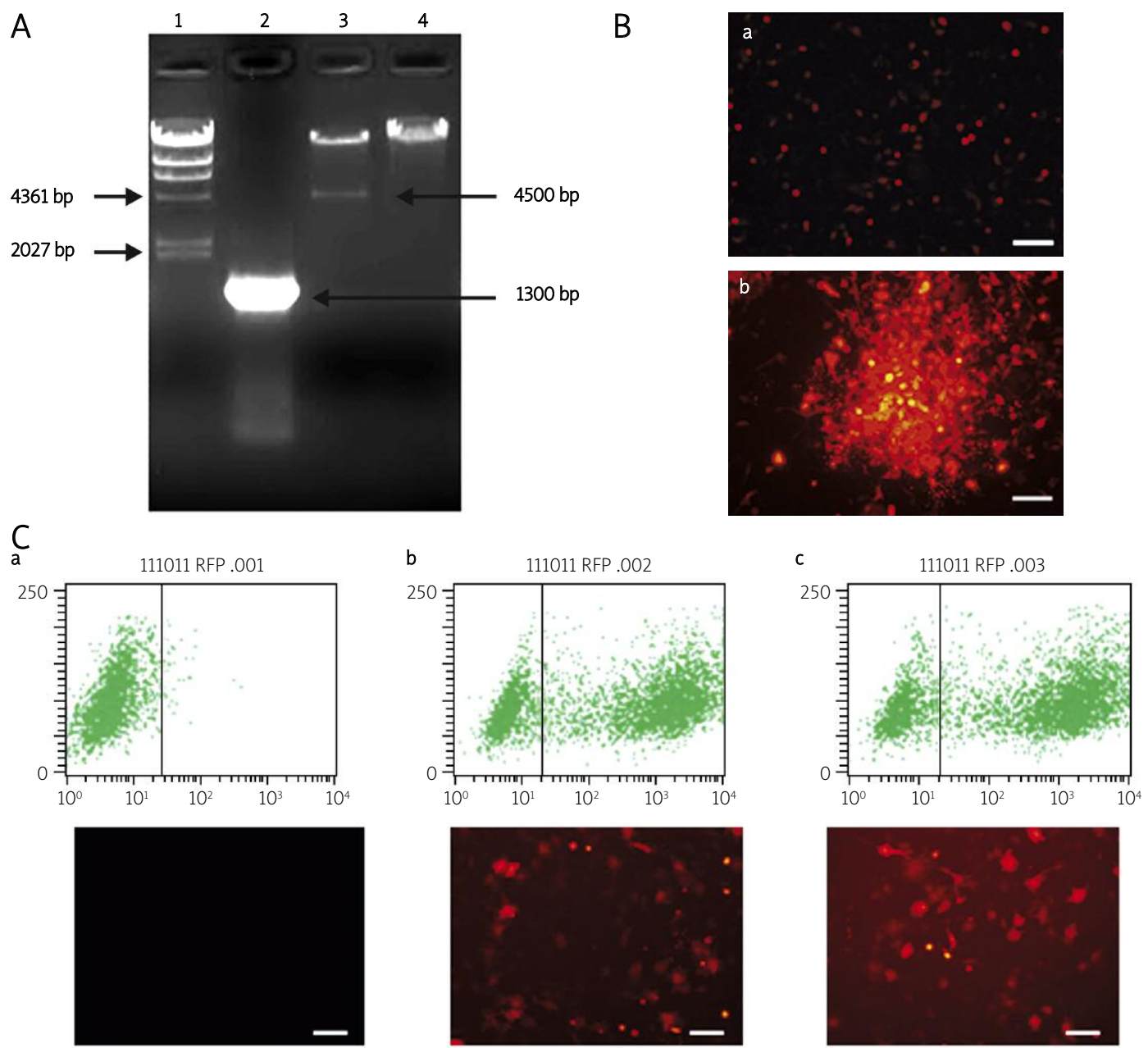

Figure 1. Construction and identification of adenovirus Ad-RAR- $\beta$. A - Identification of recombinant pAd-RAR- $\beta$ plasmid by PCR amplification and enzyme digestion. 1 - $\lambda$-HinD III DNA marker, 2 - full length of RAR- $\beta$ PCR amplified from pAd-RAR- $\beta$, 3 - pAd-RAR- $\beta$ digested by Pac I enzyme, 4 - pAdEasy- 1 bone vector digested by Pac I enzyme as negative control. B - Package of Ad-RAR- $\beta$ in HEK293 cells. After digestion by Pac I enzyme and purification, pAd-RAR- $\beta$ was liposome transfected into HEK293 cells. a - pAd-RAR- $\beta$ transfected HEK293 cells at 1d. b-Cloudiness amplification of adenovirus Ad-RAR- $\beta$ was observed in HEK293 cells at 10d pAd-RAR- $\beta$ transfection. $C$ - Infected efficacy of adenovirus Ad-RAR- $\beta$ in MSCs. a - Uninfected MSCs, b-Ad-null infected MSCs, c - Ad-RAR- $\beta$ infected MSCs (Scale bar $=200 \mu \mathrm{m}$ )

restriction enzyme from the pAd-RAR- $\beta$ plasmid and compared with pAdEasy-1 bone vector (Figure $1 \mathrm{~A}$ ). The target genes were confirmed to be correctly cloned in the adenovirus vector by gene sequencing and matched to the RAR- $\beta$ sequence in GenBank. The pAdTrace-TOX vector contains an RFP code region driven by the CMV promoter. Thus, we can check RFP to measure the transfection and infection efficiency. At $24 \mathrm{~h}$ post $\mathrm{Pac}$ I linearized pAd-RAR- $\beta$ plasmid transfection, more than $10 \%$ of HEK293 cells were RFP positive. Amplification of Ad-RAR- $\beta$ exhibited cloudiness in the HEK293 cell line at day 10 during package (Figure $1 \mathrm{~B}$ ). This result demonstrated that the recombinant adenovirus vector containing the rat RAR- $\beta$ gene was successfully constructed.

\section{Ad-RAR- $\beta$ over-expressed RAR- $\beta$ in MSCS}

Ad-RAR- $\beta$ was added to infect MSCs. After 48 h of infection, $71.61 \%$ of RFP-positive MSCs were observed.
Meanwhile, $69.63 \%$ of RFP-positive MSCs with Adnull infection were taken as the control. From realtime PCR and western blot results, we found that MSCs hardly expressed endogenous RAR- $\beta$, Ad-null infection did not affect the expression of RAR- $\beta$, and Ad-RAR- $\beta$ adenovirus could significantly induce high expression of RAR- $\beta$ (Figures $2 \mathrm{~A}, \mathrm{~B}$ ). The immunofluorescence picture showed the nuclear localization of exogenous RAR- $\beta$ over-expression (Figure $2 \mathrm{C}$ ). Therefore, Ad-RAR- $\beta$ could effectively infect MSCs and increase the mRNA and protein expression of RAR- $\beta$.

\section{RAR- $\beta$ over-expression improved ATRA-induced neuronal differentiation of MSCS}

As we previous described, ATRA treatment could improve neuronal differentiation and only stimulate expression of the RAR- $\beta$ [11]. As a neuron-specific receptor, RAR- $\beta$ is necessarily required in neuron development and is widespread in different neuron 

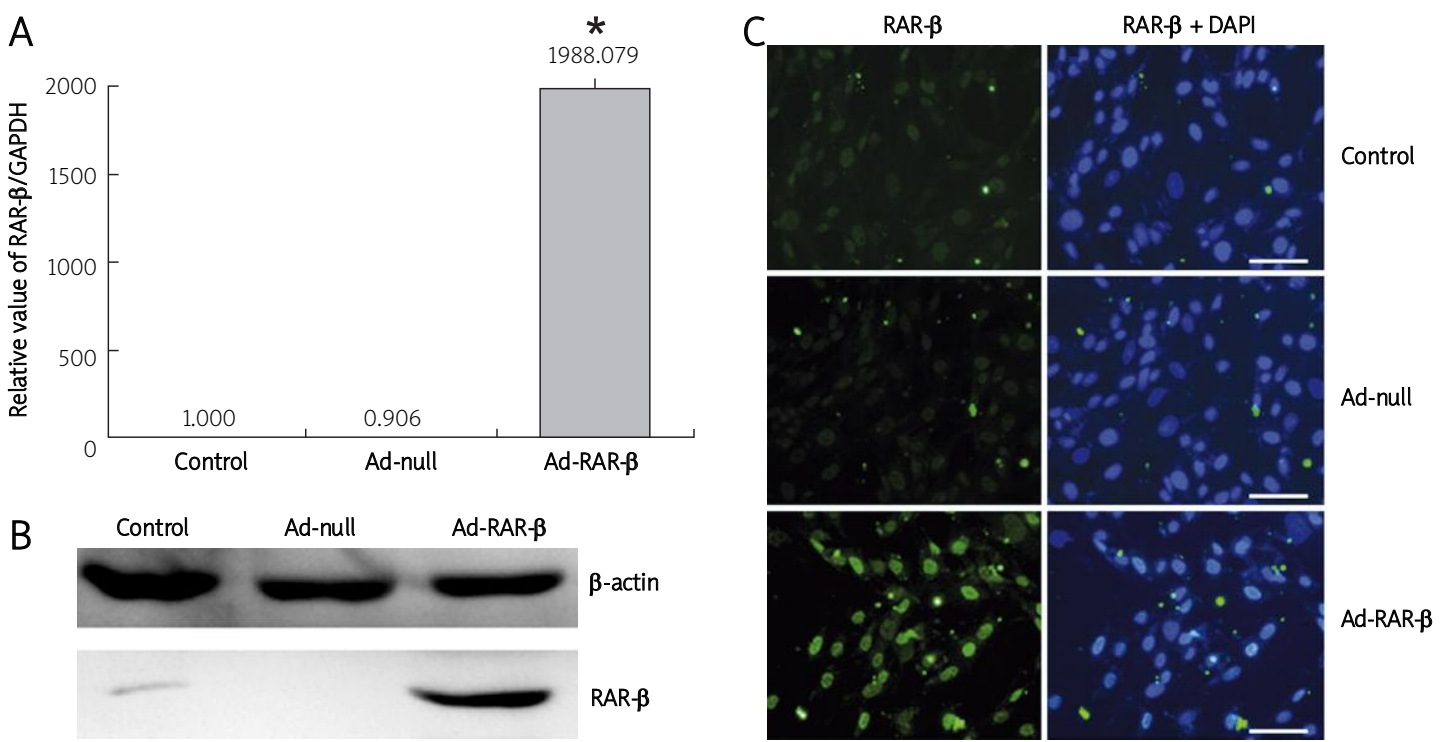

Figure 2. Adenovirus Ad-RAR- $\beta$ infection mediates over-expression of RAR- $\beta$ in rat MSCs. The MSCs were infected with adenovirus Ad-RAR- $\beta$ for $48 \mathrm{~h}$, and untreated MSCs and Ad-null infected MSCs were used as controls. A - Total RNA of cells in different treated group was extracted and reverse transcribed into cDNA template. Expression of RAR- $\beta$ was analyzed with GAPDH normalization. Real-time PCR results were confirmed in at least three batches of independent experiments ( $n=3,{ }^{*} p<0.05$ vs. Ad-null/ ATRA/MNM group). B - Cells were lysed and subjected to SDS-PAGE and western blotting using RAR- $\beta$ antibody. Equal loading of the samples was confirmed by $\beta$-actin expression. $\mathbf{C}-$ Localization and expression of RAR- $\beta$ was detected by immunofluorescence staining. Cells were fixed and probed with primary antibodies against RAR- $\beta$, followed by staining with DyLight 488 labeled secondary antibodies and staining of nuclei with DAPI. Scale bar $=200 \mu \mathrm{m}$

tissues [15]. However, RAR- $\beta$ is barely detected in MSCs. Next, we sought to determine whether overexpression of RAR- $\beta$ in MSCs could activate the ATRAinduced signal pathway and facilitate neuronal differentiation in MNM induction. As shown in Table II and Figure $3 \mathrm{~A}, 24 \mathrm{~h}$ after ATRA/MNM induction, about $88 \%$ of MSCs became retracted and refractionenhanced, exhibiting long axons or dendrites which were counted as induced neuronal cells. There was no significant difference of neuronal induction efficacy among the three treated groups. The soma sizes of ATRA/MNM, Ad-null/ATRA/MNM and Ad-RAR- $\beta$ / ATRA/MNM treated cells were $739.65 \pm 41.11 \mu \mathrm{m}^{2}$, $716.25 \pm 95.96 \mu \mathrm{m}^{2}$ and $1160.12 \pm 352.65 \mu \mathrm{m}^{2}$, respectively. Axon length is another index to evaluate neuron cells. Ad-null did not affect soma size of induced cells, but axon length of Ad-null/ATRA/MNM treated cells was shorter than that of ATRA/MNM treated cells. With Ad-RAR- $\beta$-mediated RAR- $\beta$ over-expression, induced cells exhibited longer axons (83.98 $\pm 13.69 \mu \mathrm{m})$ compared with $64.17 \pm 11.88 \mu \mathrm{m}$ of axons in Ad-null groups. Next, we detected neuronal specific markers to measure neuronal cells induced from MSCs. Real-time PCR and western blot showed that MSCs hardly expressed neuronal related markers, nestin, NSE, MAP-2, Tau and Tuj1, which were significantly increased in ATRA/MNM-induced cells. No difference was seen between ATRA/MNM and Adnull/ATRA/MNM groups. RAR- $\beta$ over-expression resulted in 4 to 11-fold higher expression of NSE, MAP-2, Tau and Tuj1, but not nestin (Figure 3 B). The above results were also confirmed by immunofluorescence staining. The expression of NSE and Tau proteins was detected in cytoplasm (Figure $3 \mathrm{C}$ ). The green fluorescence of nestin was at similar intensity among the three induction groups. NSE and Tau protein had increased expression with Ad-RAR- $\beta$ treatment (Figure $3 \mathrm{D}$ ). Taken together, we demonstrated that adenovirus-mediated RAR- $\beta$ transfection could improve neuronal differentiation of MSCS.

Table II. RAR- $\beta$ over-expression improved neuronal differentiation of MSCS

\begin{tabular}{|lccc|}
\hline Variable & ATRA + MNM & Ad-RFP + ATRA + MNM & Ad-RAR- $\beta+$ ATRA + MNM \\
\hline Neural differentiation efficiency $[\%]$ & $83.35 \pm 5.05$ & $79.20 \pm 8.62$ & $82.41 \pm 11.03$ \\
\hline Soma size $\left[\mu \mathrm{m}^{2}\right]$ & $739.65 \pm 41.11$ & $716.25 \pm 95.96$ & $1160.12 \pm 352.65^{*}$ \\
\hline Axonal length $[\mu \mathrm{m}]$ & $81.6 \pm 9.72$ & $64.17 \pm 11.88$ & $83.98 \pm 13.69^{\star}$ \\
\hline
\end{tabular}

Neuronal differentiation efficacy, soma size and axon length of induced neuron cells treated with ATRA/MNM, Ad-null/ATRA/MNM, and Ad-RAR- $\beta$ / ATRA/MNM, respectively ( $n=10,{ }^{*} p<0.05 \mathrm{vs}$. Ad-null/ATRA/MNM group) 
A
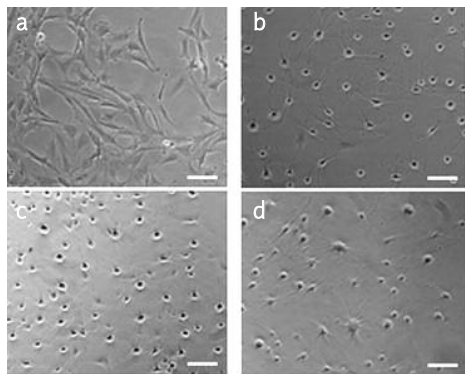

B

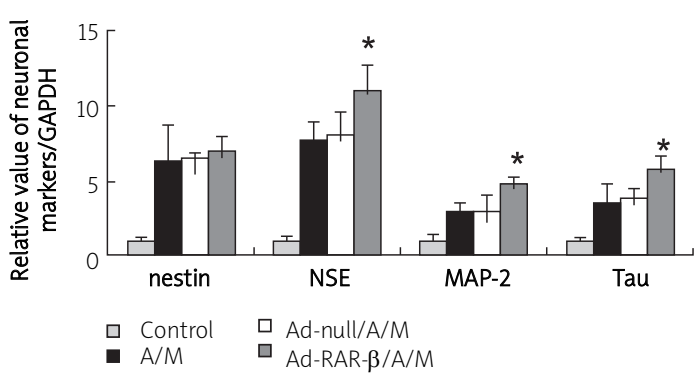

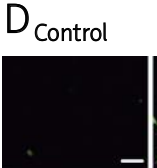

$\mathrm{A} / \mathrm{M}$ Ad-null/A/M Ad-RAR- $\beta / A / M$
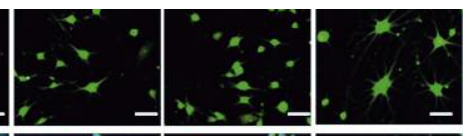

Nestin
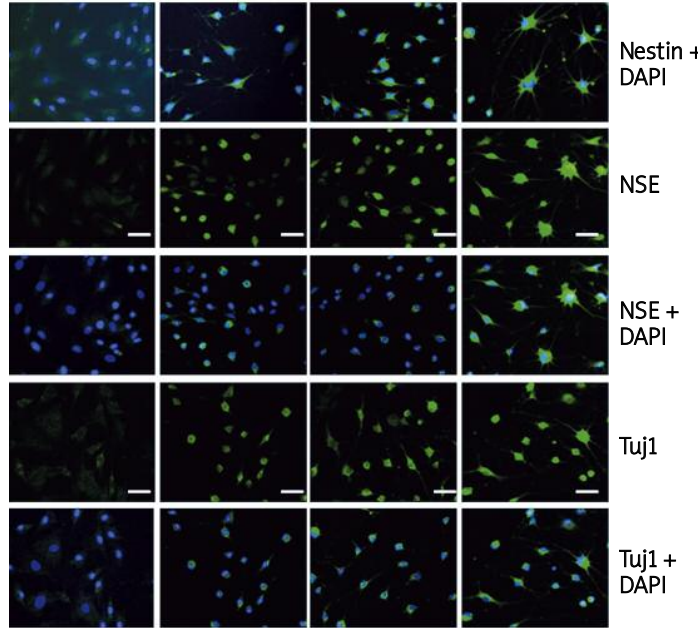

C Control A/M Ad-null/A/M Ad-RAR- $\beta / A / M$

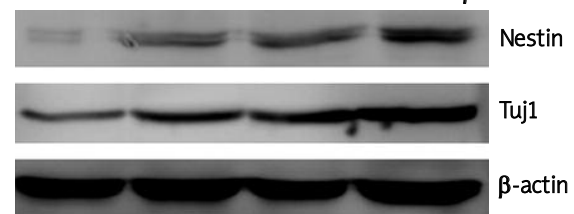

Figure 3. Ad-RAR- $\beta$ mediated RAR- $\beta$ over-expression improves neuronal differentiation of rat MSCs. Cells were divided into 4 groups. Cells in control group were untreated, cells in ATRA/MNM induction group were induced with $1 \mu \mathrm{mol} / \mathrm{l}$ ATRA for $24 \mathrm{~h}$, followed by MNM incubation for another $24 \mathrm{~h}$. Before neuronal induction, cells in Ad-null/ATRA/MNM induction group and Ad-RAR- $\beta$ /ATRA/MNM induction group were infected by adenovirus Ad-null and Ad-RAR- $\beta$ for $48 \mathrm{~h}$, respectively. A - Cell morphology, a - Control, b - ATRA/MNM treatment, c - Ad-null/ATRA/MNM treatment, $d$ - Ad-RAR- $\beta$ /ATRA/MNM treatment. B - Expression of nestin, NSE, MAP-2, and Tau was analyzed with GAPDH normalization ( $n=3,{ }^{\star} p<0.05$, Ad-RAR- $\beta$ /ATRA/MNM vs. Ad-null/ATRA/MNM). Real-time PCR results were confirmed in at least three batches of independent experiments. C - Rat MSCs were treated with ATRA for $24 \mathrm{~h}$ and collected at the indicated time points with MNM culture, then lysed and subjected to SDS-PAGE and western blot using NSE and Tuj1 antibody. Equal loading of the samples was confirmed by $\beta$-actin expression. D - Immunofluorescence staining of neural specific markers. Cells were fixed and probed with antibodies against nestin, NSE, and Tuj1 followed by staining with DyLight 488 labeled secondary antibodies and staining of nuclei with DAPI. Scale bar $=200 \mu \mathrm{m}$

\section{Discussion}

The ATRA plays very important roles in early brain development $[16,17]$. It has been demonstrated that ATRA can induce directed neuronal differentiation of embryonic stem cells (ESCS) or neuroblastoma cells $[18,19]$. The ATRA can promote neural lineage derived from ESCs by crosstalking with the ERK and Wnt pathways [20]. We previously revealed that preactivation of RA signaling by ATRA improved the efficiency of neuronal differentiation from MSCs, and also promoted maturation and function of derived neuron cells [11].

As a ligand of the RA signaling pathway, ATRA is translocated to the retinoic acid receptors (RARs) through cellular retinoic acid binding proteins (CRABP) to regulate target genes [21]. There are three subtypes of RARs, RAR- $\alpha$, RAR- $\beta$, and RAR- $\gamma$, activated in a cell type- and tissue-specific manner [22, 23]. Zechel [24] reported differential requirement of RAR isotypes during the initial stages of neural differentiation of PCC7 cells. Endogenous expression of RAR- $\alpha$ and RAR- $\gamma$ is detectable in MSCs, but RAR- $\beta$ rarely exhibits it. Combination of ATRA pretreatment with MNM induction is a mature method to induce neuronal differentiation of MSCs. However, only RAR- $\beta$ was selectively upregulated by 24 h ATRA pretreatment and had a higher increased expression in induced neuron cells compared with RAR- $\alpha$ and RAR- $\gamma$, indicating ATRA activation and neuronal differentiation mediated through RAR- $\beta$ in MSCs [11]. RAR- $\beta$ might be an important factor to activate the RA signaling pathway in developing neuronal differentiation of MSCs in vitro. So, we hypothesize that, if MSCs have a relatively high expression of RAR- $\beta$, it 
might be easier to induce MSCs to differentiate into neuron cells by ATRA and MNM induction.

Here, we tried to over-express exogenous RAR- $\beta$ and determine its role in neuronal induction of MSCs. Because of stem cell derivation, a general eukaryotic expression vector is hardly transfected into MSCs by lipofection or calcium phosphate coprecipitation [25]. In this study, we successfully constructed an adenovirus vector carrying the RAR- $\beta$ gene by using the replication-defective AdEasy adenovirus system. Ad-RAR- $\beta$ was confirmed to infect MSCs with efficacy of more than $60 \%$, and significantly enhance mRNA and protein expression level of RAR- $\beta$. RAR- $\beta$ is classified as a nuclear receptor to regulate the transcription of adjacent genes [26]. Immunofluorescence results indicated nuclear localization of RAR- $\beta$ in MSCs, suggesting that Ad-RAR- $\beta$ can induce a biologically active RAR- $\beta$ form.

It has been reported that ATRA dose-dependently affects target gene expression [27]. We previously detected the effect of different concentrations of ATRA on neuronal differentiation of MSCs and found that $1 \mu \mathrm{mol} / \mathrm{l}$ of ATRA pretreatment may induce neuron cells with the longest axon and soma diameter, and the highest expression of neuronal specific markers. Actually, ATRA at $10 \mu \mathrm{mol} / \mathrm{l}$ was also as good as, if not better than, ATRA at $1 \mu \mathrm{mol} / \mathrm{l}$ in the role of neuronal induction. However, the high cell death rate under this circumstance was a major problem; the reason might be the cytotoxicity of ATRA at high concentrations [28]. So, we considered that when RAR- $\beta$ is over-expressed in MSCs, $1 \mu \mathrm{mol} / \mathrm{l}$ of ATRA might be easier to activate the RA signaling pathway so that it plays a more effective role. Though induction efficiency was not distinct, soma size and axon length were improved in induced neuron cells with Ad-RAR- $\beta$ infection. Ad-null control was set up in following experiments since adenovirus might affect axon length of induced neuron cells. Most of the neuronal specific markers had increased expression with RAR- $\beta$ over-expression. Nevertheless, we did not find a change of nestin between ATRA/MNM and Ad-RAR- $\beta$ /ATRA/MNM groups. Nestin is an intermediate filament protein which is specifically expressed in neuroepithelial stem cells, and can also transiently appear in other progenitor cells [29]. Nestin only expresses in neural epithelium at an early stage of embryonic development, and stops expression after birth [30, 31]. During the ATRA/MNMinduced neuronal differentiation process, the expression of nestin increased within the first $18 \mathrm{~h}$ and decreased quickly. The Ad-RAR- $\beta$ /ATRA/MNM-induced neuron cells crossed the peak of nestin expression, and only a low level of nestin expression was found in the mature neuron cells.

In conclusion, we demonstrated that adenovirusmediated RAR- $\beta$ over-expression in MSCs could improve ATRA-induced neuronal differentiation of MSCs in following MNM induction, providing us with a promising method for neuronal differentiation in vitro. As a neural specific receptor, RAR- $\beta$ is also a critical candidate molecule for RA signal activation. Further studies on RAR- $\beta$ should contribute to the biochemical mechanism of the RA signaling pathway in neuronal development and differentiation.

\section{Acknowledgments}

Yang Bi and Min Gong contributed equally to the work.

This work was supported by grants from the National Natural Science Foundation of China (30830106 and 81100309), China Postdoctoral Science Foundation (20100480667), Natural Science Foundation of Chongqing City (CSTC2010BB5097), and the health bureau of Chongqing (2010-2-217).

\section{References}

1. Martinez-Biarge M, Diez-Sebastian J, Kapellou O, et al. Predicting motor outcome and death in term hypoxic-ischemic encephalopathy. Neurology 2011; 76: 2055-61.

2. Corti S, Nizzardo M, Nardini M, et al. Neural stem cell transplantation can ameliorate the phenotype of a mouse model of spinal muscular atrophy. J Clin Invest 2008; 118: 3316-30.

3. Pimentel-Coelho PM, Mendez-Otero R. Cell therapy for neonatal hypoxic-ischemic encephalopathy. Stem Cells Dev 2010; 19: 299-310.

4. Baksh D, Song L, Tuan RS. Adult mesenchymal stem cells: characterization, differentiation, and application in cell and gene therapy. J Cell Mol Med 2004; 8: 301-16.

5. Hofstetter CP, Schwarz EJ, Hess D, et al. Marrow stromal cells form guiding strands in the injured spinal cord and promote recovery. Proc Natl Acad Sci U S A 2002; 99: 2199-204.

6. Choong PF, Mok PL, Cheong SK, Leong CF, Then KY. Generating neuron-like cells from BM-derived mesenchymal stromal cells in vitro. Cytotherapy 2007; 9: 170-83.

7. Liu Y, Zhang X, Dai Y, et al. Effects of bone marrow mesenchymal stem cells on learning and memory functional recovery in neonatal rats with hypoxic-ischemic brain damage. Zhonghua Er Ke Za Zhi 2008; 46: 648-53.

8. Woodbury D, Schwarz EJ, Prockop DJ, Black IB. Adult rat and human bone marrow stromal cells differentiate into neurons. J Neurosci Res 2000; 61: 364-70.

9. Niederreither K, Dollé P. Retinoic acid in development: towards an integrated view. Nat Rev Genet 2008; 9: 541-53.

10. Siegenthaler JA, Ashique AM, Zarbalis K, et al. Retinoic acid from the meninges regulates cortical neuron generation. Cell 2009; 139: 597-609.

11. Bi Y, Gong M, Zhang X, et al. Pre-activation of retinoid signaling facilitates neuronal differentiation of mesenchymal stem cells. Dev Growth Differ 2010; 52: 419-31.

12. Gong M, Bi Y, Jiang W, Zhang Y, et al. Immortalized mesenchymal stem cells: an alternative to primary mesenchymal stem cells in neuronal differentiation and neuroregeneration associated studies. J Biomed Sci 2011; 18: 87.

13. He TC, Zhou S, da Costa LT, Yu J, Kinzler KW, Vogelstein B. A simplified system for generating recombinant adenoviruses. Proc Natl Acad Sci U S A 1998; 95: 2509-14.

14. Bi Y, Huang J, He Y, et al. Wnt antagonist SFRP3 inhibits the differentiation of mouse hepatic progenitor cells. J Cell Biochem 2009; 108: 295-303.

15. Jiang W, Wen EY, Gong M, et al. The pattern of retinoic acid receptor expression and subcellular, anatomic and 
functional area translocation during the postnatal development of the rat cerebral cortex and white matter. Brain Res 2011; 1382: 77-87.

16. Wohl CA, Weiss S. Retinoic acid enhances neuronal proliferation and astroglial differentiation in cultures of CNS stem cell-derived precursors. J Neurobiol 1998; 37: 281-90.

17. Clagett-Dame M, McNeill EM, Muley PD. Role of all-trans retinoic acid in neurite outgrowth and axonal elongation. Jeurobiol 2006; 66: 739-56.

18. Wada T, Honda M, Minami I, et al Highly efficient differentiation and enrichment of spinal motor neurons derived from human and monkey embryonic stem cells. PLoS One 2009; 4: e6722.

19. Sallmon H, Hoene V, Weber SC, Dame C. Differentiation of human SH-SY5Y neuroblastoma cells by all-trans retinoic acid activates the interleukin-18 system. J Interferon Cytokine Res 2010; 30: 55-8.

20. Lu J, Tan L, Li P, et al. All-trans retinoic acid promotes neural lineage entry by pluripotent embryonic stem cells via multiple pathways. BMC Cell Biol 2009; 10: 57.

21. Bushue N, Wan YJ. Retinoid pathway and cancer therapeutics. Adv Drug Deliv Rev 2010; 62: 1285-98.

22. Mollard R, Viville S, Ward SJ, Décimo D, Chambon P, Dollé P. Tissue-specific expression of retinoic acid receptor isoform transcripts in the mouse embryo. Mech Dev 2000; 94: 223-32.

23. Gillespie RF, Gudas LJ. Retinoic acid receptor isotype specificity in F9 teratocarcinoma stem cells results from the differential recruitment of coregulators to retinoic response elements. J Biol Chem 2007; 282: 33421-34.

24. Zechel C. Requirement of retinoic acid receptor isotypes alpha, beta, and gamma during the initial steps of neural differentiation of PCC7 cells. Mol Endocrinol 2005; 19: 1629-45.

25. Chen XA, Zhang LJ, He ZJ, et al. Plasmid-encapsulated polyethylene glycol-grafted polyethylenimine nanoparticles for gene delivery into rat mesenchymal stem cells. Int J Nanomedicine 2011; 6: 843-53.

26. James SY, Lin F, Kolluri SK, Dawson MI, Zhang XK. Regu lation of retinoic acid receptor beta expression by peroxisome proliferator-activated receptor gamma ligands in cancer cells. Cancer Res 2003; 63: 3531-8.

27. Takamura K, Nasuhara Y, Kobayashi M, et al. Retinoic acid inhibits interleukin-4-induced eotaxin production in a human bronchial epithelial cell line. Am J Physiol Lung Cell Mol Physiol 2004; 286: L777-85.

28. Díaz C, Vargas E, Gätjens-Boniche O. Cytotoxic effect induced by retinoic acid loaded into galactosyl-sphingosine containing liposomes on human hepatoma cell lines. Int J Pharm 2006; 325: 108-15.

29. Wagner N, Wagner KD, Scholz H, Kirschner KM, Schedl A. Intermediate filament protein nestin is expressed in developing kidney and heart and might be regulated by the Wilms' tumor suppressor Wt1. Am J Physiol Regul Integr Comp Physiol 2006; 291: R779-87.

30. Hendrickson ML, Rao AJ, Demerdash ON, Kalil RE. Expression of nestin by neural cells in the adult rat and human brain. PLoS One 2011; 6: e18535.

31. Park D, Xiang AP, Mao FF, et al. Nestin is required for the proper self-renewal of neural stem cells. Stem Cells 2010; 28: 2162-71. 


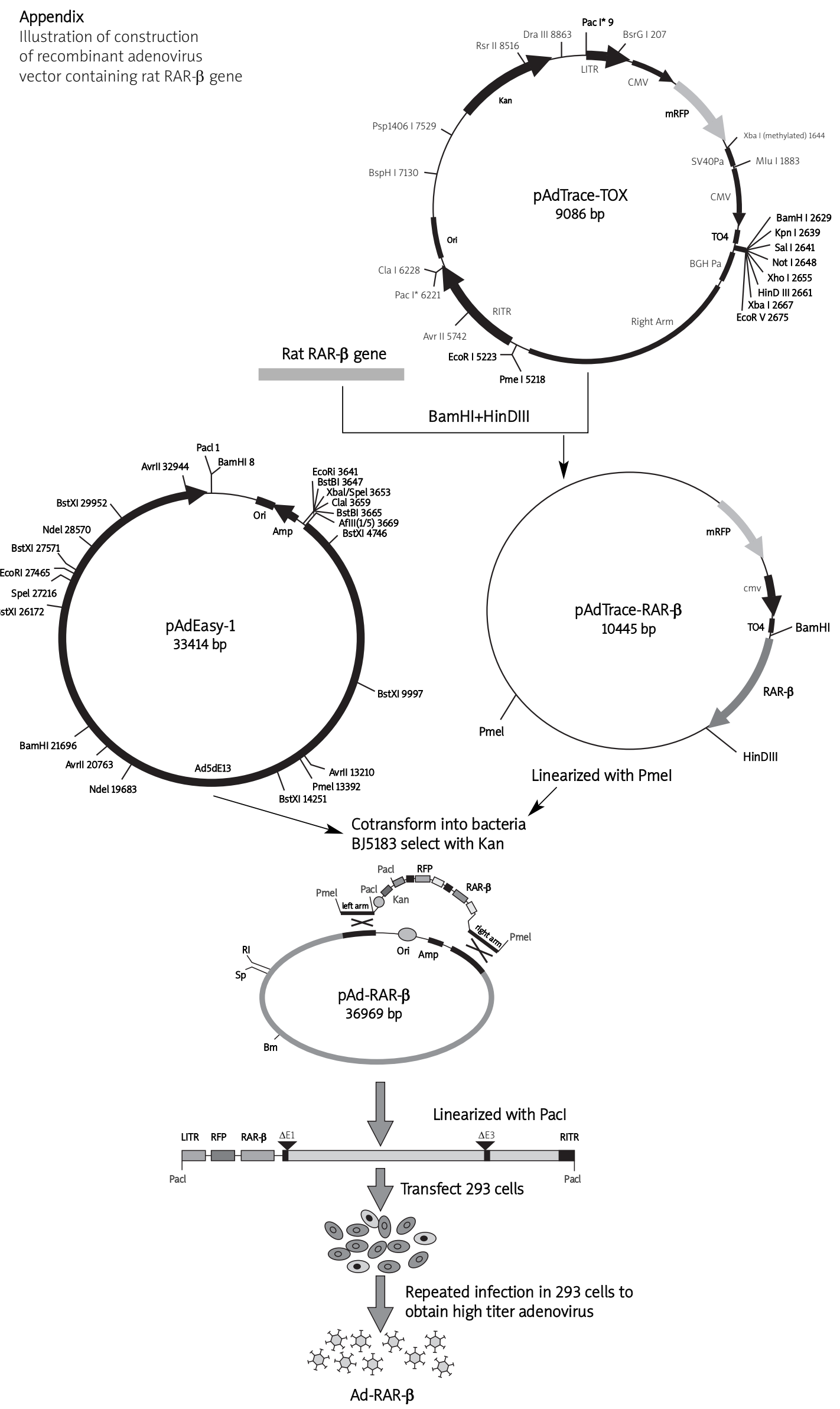

